\title{
Pharmacokinetic and Pharmacodynamic Properties of Faster- Acting Insulin Aspart versus Insulin Aspart Across a Clinically Relevant Dose Range in Subjects with Type 1 Diabetes Mellitus
}

\author{
Tim Heise ${ }^{1} \cdot$ Kirstine Stender-Petersen $^{2} \cdot$ Ulrike Hövelmann $^{1} \cdot$ Jacob Bonde Jacobsen $^{2}$. \\ Leszek Nosek ${ }^{1} \cdot$ Eric Zijlstra $^{1}$ - Hanne Haahr ${ }^{2}$
}

Published online: 22 November 2016

(c) The Author(s) 2016. This article is published with open access at Springerlink.com

\begin{abstract}
Background Absorption of current rapid-acting insulins is too slow for patients with diabetes mellitus to achieve optimal postprandial glucose control. Faster-acting insulin aspart (faster aspart) is insulin aspart in a new formulation with faster early absorption. We compared the pharmacokinetic/pharmacodynamic properties of faster aspart and insulin aspart across a clinically relevant dose range.

Methods In this randomised, double-blind, crossover trial, 46 subjects with type 1 diabetes mellitus received single subcutaneous doses of faster aspart and insulin aspart at $0.1,0.2$ (repeated three times to estimate within-subject variability) and $0.4 \mathrm{U} / \mathrm{kg}$ in a euglycaemic clamp setting (target $5.5 \mathrm{mmol} / \mathrm{L}$ ).

Results Consistently for the three doses, faster aspart demonstrated faster onset and greater early absorption and glucose-lowering effect versus insulin aspart. Across all three doses, onset of appearance occurred approximately twice as fast (approximately $5 \mathrm{~min}$ earlier) and early insulin exposure $\left(\mathrm{AUC}_{\mathrm{IAsp}, 0-30 \mathrm{~min}}\right)$ was approximately 1.5to 2-fold greater for faster aspart versus insulin aspart. Likewise, onset of action occurred approximately $5 \mathrm{~min}$ faster and early glucose-lowering effect $\left(\mathrm{AUC}_{\mathrm{GIR}, 0-30 \mathrm{~min}}\right)$
\end{abstract}

Electronic supplementary material The online version of this article (doi:10.1007/s40262-016-0473-5) contains supplementary material, which is available to authorized users.

Tim Heise

tim.heise@profil.com

1 Profil Institut für Stoffwechselforschung GmbH, Hellersbergstrasse 9, 41460 Neuss, Germany

2 Novo Nordisk A/S, Vandtårnsvej 114, 2860 Søborg, Denmark was approximately 1.5- to 2-fold larger for faster aspart versus insulin aspart. Relative bioavailability was approximately $100 \%$ and total glucose-lowering effect was similar for faster aspart versus insulin aspart. Dose-concentration and dose-response relationships were comparable between faster aspart and insulin aspart. Within-subject variability in glucose-lowering effect was low for faster aspart (coefficient of variation approximately 20\%) and not significantly different from insulin aspart.

Conclusion The faster onset and greater early insulin exposure and glucose-lowering effect with faster aspart versus insulin aspart are preserved across a broad range of doses and consistently observed from day to day. ClinicalTrials.gov identifier NCT02033239.

\section{Key Points}

Onset of appearance was twice as fast, and early insulin exposure and glucose-lowering effect were up to twofold greater, with faster-acting insulin aspart compared with insulin aspart across a clinically relevant dose range of $0.1-0.4 \mathrm{U} / \mathrm{kg}$ in subjects with type 1 diabetes mellitus.

Within-subject day-to-day variability in early and total glucose-lowering effect was low for fasteracting insulin aspart and comparable with insulin aspart, with coefficients of variation for both insulins in the range of $18-25 \%$.

Faster-acting insulin aspart has the pharmacological properties to provide clinical benefits over current rapid-acting insulin analogues in terms of improved postprandial glucose control. 


\section{Introduction}

Achievement of recommended glycosylated haemoglobin $\left(\mathrm{HbA}_{1 \mathrm{c}}\right)$ targets in patients with diabetes requires optimisation of postprandial glucose control $[1,2]$. The development of rapid-acting insulin analogues (insulin aspart, insulin lispro and insulin glulisine) has provided improved postprandial glycaemia through accelerated absorption and earlier onset of action compared with regular human insulin [3-5]. Nonetheless, even with rapid-acting insulin analogues, absorption is too slow to achieve optimal control of postprandial glucose when administered at the start of the meal [6-8]. It has been shown that administration of current rapid-acting insulin approximately $15 \mathrm{~min}$ before the start of the meal provides the best possible postprandial glycaemia with these products [7]. The injection-meal interval compensates for the delay from subcutaneous injection until the circulating insulin concentration becomes sufficient to match the carbohydrate uptake following a meal [8]; however, in accordance with current labelling, and for ease and convenience, many patients with diabetes use a shorter or no injection-meal interval [9]. Thus, there is a need for insulins with more rapid pharmacological properties that better mimic the endogenous prandial insulin secretion in healthy individuals.

Faster-acting insulin aspart (faster aspart) is insulin aspart in a new formulation including two well-known additional excipients, L-arginine and niacinamide, which provide a stable formulation with faster early absorption. L-arginine and niacinamide are both listed in the US FDA inactive ingredient database, in products for injection, at higher concentrations than used in faster aspart [10]. In a previous trial in subjects with type 1 diabetes mellitus (T1DM), a single dose of faster aspart $0.2 \mathrm{U} / \mathrm{kg}$ provided twice as fast onset of appearance, twofold greater early insulin exposure and 50\% greater early glucose-lowering effect within the first $30 \mathrm{~min}$ after injection compared with insulin aspart [11].

In patients with diabetes, mealtime insulin requirements can vary substantially depending on carbohydrate content and glycaemic index of the meal. It is therefore important to assess whether the improved pharmacological properties of faster aspart versus insulin aspart at $0.2 \mathrm{U} / \mathrm{kg}$ [11] are also found across a broader dose range. Moreover, as reliable titration of an insulin product depends on an established dose-response relationship, it is pertinent to investigate the dose-concentration and dose-response relationships of any new insulin. Finally, the degree of variability in insulin action between similar consecutive insulin injections has considerable impact on the ability to achieve strict glycaemic control without the risk of hypoglycaemia $[12,13]$. Thus, it is highly relevant to investigate within-subject variability in the glucose-lowering effect of faster aspart.

In this glucose clamp study, we compared faster aspart and insulin aspart with respect to pharmacokinetic and pharmacodynamic properties across three clinically relevant dose levels $(0.1,0.2$ and $0.4 \mathrm{U} / \mathrm{kg})$. Furthermore, we investigated the dose-concentration and dose-response relationships of faster aspart, and compared the withinsubject variability in glucose-lowering effect between faster aspart and insulin aspart. The study was conducted in subjects with T1DM, who are regarded as the optimal population in glucose clamp studies because the glucoselowering effect can be compared between exogenous insulins without interference from endogenous insulin secretion [14].

\section{Methods}

\subsection{Study Design and Participants}

This was a randomised, single-centre (Profil, Neuss, Germany), double-blind, eight-period, crossover trial. The local health authority (Bundesinstitut für Arzneimittel und Medizinprodukte) and an independent ethics committee (Ärztekammer Nordrhein) reviewed and approved the trial protocol. The trial was registered at ClinicalTrials.gov (trial identifier: NCT02033239).

Eligible subjects were men and women 18-64 years of age (both inclusive), with T1DM for $\geq 12$ months before inclusion in the trial, treated with multiple daily insulin injections or continuous subcutaneous insulin infusion for $\geq 12$ months [total daily insulin dose $<1.2$ (I) $\mathrm{U} / \mathrm{kg} /$ day and total daily bolus insulin dose $<0.7$ (I) $\mathrm{U} / \mathrm{kg} /$ day], with $\mathrm{HbA}_{1 \mathrm{c}} \leq 9.0 \%(\leq 75 \mathrm{mmol} / \mathrm{mol})$, body mass index (BMI) of $18.5-28.0 \mathrm{~kg} / \mathrm{m}^{2}$ (both inclusive) and fasting C-peptide $\leq 0.3 \mathrm{nmol} / \mathrm{L}$. Subjects were excluded if they had clinically significant concomitant diseases, clinically significant abnormal values in clinical laboratory screening tests, were smokers or were currently treated with other drug(s) that may interfere with glucose metabolism.

Informed consent was obtained from all individual participants included in the study.

\subsection{Procedures}

The trial consisted of 10 visits: a screening visit, eight dosing visits separated by a 3- to 15-day washout period, and a follow-up visit. All subjects received three dose levels $(0.1,0.2$ and $0.4 \mathrm{U} / \mathrm{kg})$ of faster aspart and insulin aspart to compare the pharmacokinetic and pharmacodynamic properties between treatments, and to investigate the dose-concentration and dose-response relationships. To 
estimate the within-subject variability, subjects were randomised to receive either two additional doses of faster aspart $0.2 \mathrm{U} / \mathrm{kg}$ or two additional doses of insulin aspart 0.2 U/kg (Fig. 1). The eight dosing visits were conducted in randomised sequence.

The trial products were faster aspart $(100 \mathrm{U} / \mathrm{mL}$; Novo Nordisk, Bagsværd, Denmark) and insulin aspart (NovoRapid $^{\circledR} ; 100 \mathrm{U} / \mathrm{mL}$; Novo Nordisk), both in a blinded PDS290 pen-injector prefilled pen (Novo Nordisk). Trial products were administered by subcutaneous injection into a lifted skinfold of the lower abdominal wall above the inguinal area by a qualified person with no other tasks in the study, to keep its double-blind nature.

At each dosing visit, subjects attended the clinical site in the morning after having fasted since $2200 \mathrm{~h}$ the evening before (except for water ad libitum and $\leq 20 \mathrm{~g}$ of rapidly absorbable carbohydrate if needed to prevent hypoglycaemia). A euglycaemic glucose clamp procedure (ClampArt ${ }^{\circledR}$; Profil) was then conducted as previously described [11]. Initially, subjects received a variable intravenous infusion of regular human insulin [15 IU Actrapid $^{\circledR}$ (100 IU/mL; Novo Nordisk) in $49 \mathrm{~mL}$ saline and $1 \mathrm{~mL}$ of the subject's blood] or glucose $(20 \%)$ for 1-4 h before dosing to obtain a blood glucose target level of $5.5 \mathrm{mmol} / \mathrm{L}(100 \mathrm{mg} / \mathrm{dL})$. The intravenous insulin infusion rate was manually adjusted by attending staff based on actual blood glucose measurements, while the intravenous glucose infusion rate was automatically adjusted by ClampArt ${ }^{\circledR}$ in order to keep blood glucose at the target level throughout the glucose clamp. Dosing of the trial product occurred after blood glucose concentration had been stable for $\geq 1 \mathrm{~h}$, with no infusion of glucose. After dosing, the rate of intravenous insulin infusion (if any) was gradually reduced and terminated completely when blood glucose had fallen by $0.3 \mathrm{mmol} / \mathrm{L}(5 \mathrm{mg} / \mathrm{dL})$.
The intravenous glucose infusion was then initiated. The clamp lasted for up to $12 \mathrm{~h}$ after dosing, but was stopped earlier if blood glucose consistently exceeded $11.1 \mathrm{mmol} / \mathrm{L}$ $(200 \mathrm{mg} / \mathrm{dL})$ without the need for intravenous glucose infusion during the last $30 \mathrm{~min}$. Mean profiles of intravenous insulin infusion from $-60 \mathrm{~min}$ until blood glucose had fallen by $0.3 \mathrm{mmol} / \mathrm{L}(5 \mathrm{mg} / \mathrm{dL})$, and mean profiles of blood glucose concentration from $-60 \mathrm{~min}$ until $30 \mathrm{~min}$, are shown in Online Resource 1, Fig. S1. The quality of the conducted clamps was high and comparable across treatments and dose levels (Online Resource 1, Table S1) [15].

Blood samples for pharmacokinetic assessment were drawn within 2 min pre-dose, then every 2 min from dosing until $20 \mathrm{~min}$ post-dose, every $5 \mathrm{~min}$ from 20 to $80 \mathrm{~min}$, every $10 \mathrm{~min}$ from $80 \mathrm{~min}$ to $2 \mathrm{~h}$, every $15 \mathrm{~min}$ from 2 to $2.5 \mathrm{~h}$, and then at $3,3.5,4,5.5,7,9$ and $12 \mathrm{~h}$ post-dose.

\subsection{Assessments}

Free serum insulin aspart concentrations (polyethylene glycol-precipitated) were measured by a validated insulin aspart-specific enzyme-linked immunosorbent assay with a lower limit of quantification (LLOQ) of $10 \mathrm{pmol} / \mathrm{L}$. The glucose infusion rate needed to keep the blood glucose concentration at the clamp target level was recorded automatically every minute during the glucose clamp. Safety assessments included adverse events, local tolerability at the injection site, hypoglycaemic episodes (defined as 'confirmed' when they were either 'severe' according to the American Diabetes Association, i.e. requiring third-party assistance [16], or verified by a plasma glucose level of $<3.1 \mathrm{mmol} / \mathrm{L}[56 \mathrm{mg} / \mathrm{dL}]$ ), laboratory safety parameters, physical examination, vital signs and electrocardiogram.
Fig. 1 Study design and subject disposition. Each subject participated in a total of eight dosing visits in randomised sequence in a crossover design. All subjects received faster aspart and insulin aspart at three different dose levels $(0.1,0.2$ and $0.4 \mathrm{U} / \mathrm{kg}$ ). Moreover, in order to estimate the withinsubject variability, subjects received two additional doses of either faster aspart $0.2 \mathrm{U} / \mathrm{kg}$ or insulin aspart $0.2 \mathrm{U} / \mathrm{kg}$. All dosing visits were separated by a washout period of 3-15 days

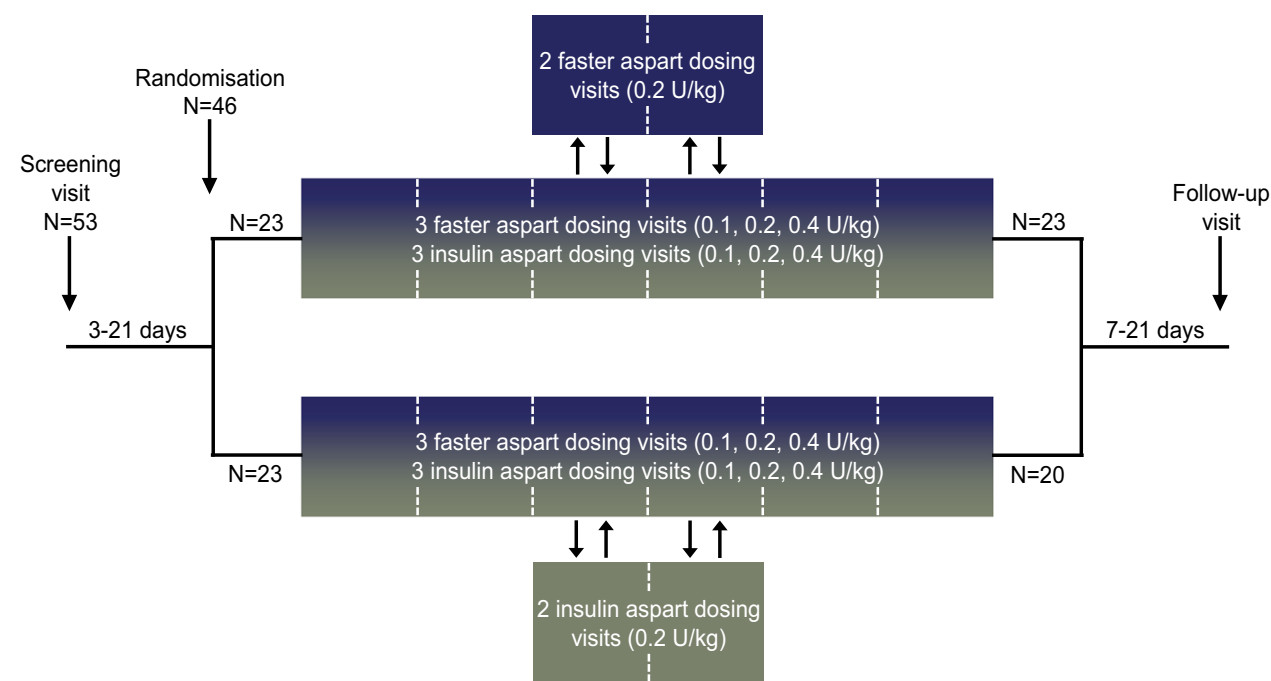




\subsection{Endpoints}

Endpoints were onset of appearance [time from trial product administration until the first-time serum insulin concentration $\geq$ LLOQ $(10 \mathrm{pmol} / \mathrm{L})$ ], time to early $50 \%$ of maximum insulin concentration $\left(t_{\text {Early }} 50 \% C_{\text {max }}\right)$, time to maximum insulin concentration $\left(t_{\max }\right)$, onset of action [time from trial product administration until the blood glucose concentration had decreased by $\geq 0.3 \mathrm{mmol} / \mathrm{L}$ $(5 \mathrm{mg} / \mathrm{dL})$ from baseline], time to early $50 \%$ of maximum glucose infusion rate $\left(t_{\text {Early }} 50 \%\right.$ GIRmax $)$, and time to maximum glucose infusion rate $\left(\mathrm{tGIR}_{\max }\right)$ [all to evaluate onset of exposure and onset of glucose-lowering effect]; early partial areas under the curve (AUCs) for serum insulin $\left(\mathrm{AUC}_{\mathrm{IAsp}, 0-15 \mathrm{~min}}, \quad \mathrm{AUC}_{\mathrm{IAsp}, 0-30 \mathrm{~min}}, \quad \mathrm{AUC}_{\mathrm{IAsp}, 0-1 \mathrm{~h}}\right.$, $\mathrm{AUC}_{\mathrm{IAsp}, 0-1.5 \mathrm{~h}}$, and $\left.\mathrm{AUC}_{\mathrm{IAsp}, 0-2 \mathrm{~h}}\right)$ and glucose infusion rate $\left(\mathrm{AUC}_{\mathrm{GIR}, 0-30 \mathrm{~min}}, \quad \mathrm{AUC}_{\mathrm{GIR}, 0-1 \mathrm{~h}}, \quad \mathrm{AUC}_{\mathrm{GIR}, 0-1.5 \mathrm{~h}, \quad \text { and }}\right.$ $\left.\mathrm{AUC}_{\mathrm{GIR}, 0-2 \mathrm{~h}}\right)$ to evaluate early exposure and early glucoselowering effect; and total exposure $\left(\mathrm{AUC}_{\mathrm{IAsp}, 0-t}\right)$, maximum concentration $\left(\mathrm{C}_{\max }\right)$, total glucose-lowering effect ( $\mathrm{AUC}_{\mathrm{GIR}, 0-t}$; primary endpoint), and maximum glucose infusion rate $\left(\mathrm{GIR}_{\max }\right)$ to evaluate overall exposure and glucose-lowering effect.

For calculation of onset of appearance and $\mathrm{AUC}_{\mathrm{IAsp}, 0-15 \mathrm{~min}}$, insulin aspart concentration was imputed during the time interval from dosing until the time of the first observed insulin aspart concentration above LLOQ using compartmental modelling (see Online Resource 1, page 4 for details). For consistency, this approach was also used for the initial part of the AUC in the calculation of all other $\mathrm{AUC}_{\mathrm{IAsp}}$ endpoints. $\mathrm{AUC}_{\mathrm{IAsp}, 0-\mathrm{t}}$ was derived by calculating the AUC until the time of the last quantifiable insulin aspart concentration, and then extrapolating until $12 \mathrm{~h}$ (last pharmacokinetic sampling time point) based on the terminal slope. $\mathrm{AUC}_{\mathrm{GIR}, 0-\mathrm{t}}$ was calculated until the time of the last observed glucose infusion rate $>0$. Endpoints were derived from the raw profiles, except for $t_{\text {Early }} 50 \%$ GIRmax, $\mathrm{GIR}_{\max }$ and $\mathrm{tGIR}_{\max }$, which were derived from LOESS smoothed glucose infusion rate profiles (using a smoothing factor of 0.1 ) in order to ensure robust calculation of these endpoints.

\subsection{Statistical Analyses}

\subsubsection{General Statistical Considerations}

Statistical analyses were conducted using SAS version 9.3 (SAS Institute, Cary, NC, USA) at a 5\% significance level based on all randomised subjects receiving at least one dose of trial product. Safety endpoints were summarised by descriptive statistics, also based on all subjects receiving at least one dose of trial product. Unless otherwise stated (post hoc analyses), the statistical analyses conducted were planned prior to database lock.

\subsubsection{Sample Size Calculation}

Based on the primary endpoint, $\mathrm{AUC}_{\mathrm{GIR}, 0-t}$, the number of completers required in this trial was 24 subjects to obtain $\geq 90 \%$ power for distinguishing between the three faster aspart dose levels, assuming true ratios for $\mathrm{AUC}_{\mathrm{GIR}, 0-t}$ of $1.35(0.2$ vs. $0.1 \mathrm{U} / \mathrm{kg}$, and 0.4 vs. $0.2 \mathrm{U} / \mathrm{kg}$ ) and a withinsubject standard deviation (on the log-scale) of 0.31 (from a previous trial with faster aspart [11]). However, in order to obtain sufficient power also for evaluating differences between faster aspart and insulin aspart, the number of required completers was increased to 40 subjects. This yielded $80 \%$ power for detecting a geometric mean treatment ratio of 1.2 for $\mathrm{AUC}_{\mathrm{GIR}, 0-1 \mathrm{~h}}$ based on an assumed within-subject standard deviation (on the log-scale) of 0.29 [11].

\subsubsection{Analysis of Onset, Exposure and Glucose-Lowering Effect}

Pharmacokinetic and pharmacodynamic endpoints were log-transformed (except onset of exposure endpoints, onset of glucose-lowering effect endpoints, $\mathrm{AUC}_{\mathrm{GIR}, 0-30 \mathrm{~min}}$ and $\left.\mathrm{AUC}_{\mathrm{GIR}, 0-1 \mathrm{~h}}\right)$ and compared between faster aspart and insulin aspart at each dose level (post hoc for $\mathrm{AUC}_{\mathrm{GIR}, 0-t}$ ) in a linear mixed model, with period, treatment, dose and the interaction between treatment and dose as fixed effects and subject as a random effect. For endpoints that were not log-transformed, the model further included an interaction between subject and dose as a random effect, and the variance parameters were dependent on dose. For endpoints that were not log-transformed, treatment ratios and 95\% confidence intervals (CIs) were calculated using Fieller's method [17].

\subsubsection{Analysis of Dose-Concentration and Dose-Response}

To investigate the dose-concentration relationship, $\mathrm{AUC}_{\mathrm{IAsp}, 0-t}$ and $C_{\max }$ were log-transformed and analysed using a linear mixed model, with treatment and period as fixed effects, log-dose and an interaction between treatment and log-dose as covariates, and subject as a random effect. The $\log -\mathrm{AUC}_{\mathrm{IAsp}, 0-t}$ versus $\log$-dose, and the $\log$ $C_{\max }$ versus log-dose slopes, were estimated for each treatment, and it was tested if the slope for faster aspart was different from 1.00 (indicating a deviation from dose proportionality) and if the slopes differed between treatments (post hoc).

To investigate the dose-response relationship, ratios (and 95\% CIs) between dose levels were estimated within each treatment for $\mathrm{AUC}_{\mathrm{GIR}, 0-t}$ using the same model as described in Sect. 2.5.3 for $\mathrm{AUC}_{\mathrm{GIR}, 0-t}$ (primary analysis). To further explore the functional form of 
the dose-response relationship, $\mathrm{AUC}_{\mathrm{GIR}, 0-t}$ and $\mathrm{GIR}_{\max }$ were log-transformed and analysed using a non-linear mixed model, with period as a fixed effect, subject as a random effect, and a quadratic function of dose on the original scale as a covariate, depending on treatment. For each treatment, it was tested if the second-order coefficient describing the curvature of the dose-response relationship was statistically different from zero (indicating deviation from dose linearity). Moreover, the functional form of the dose-response relationship was compared between treatments by simultaneously testing if the coefficients describing the dose-response relationship differed between treatments.

\subsubsection{Analysis of Within- and Between-Subject Variability in Glucose-Lowering Effect}

To compare the within- and between-subject variability in glucose-lowering effect between faster aspart and insulin aspart, $\mathrm{AUC}_{\mathrm{GIR}, 0-1 \mathrm{~h}}, \mathrm{AUC}_{\mathrm{GIR}, 0-2 \mathrm{~h}}$ (both post hoc), $\mathrm{AUC}_{\mathrm{GIR}, 0-t}$ and $\mathrm{GIR}_{\max }$ (both post hoc for between-subject variability) were analysed separately for the three dose administrations of faster aspart $0.2 \mathrm{U} / \mathrm{kg}$ and insulin aspart $0.2 \mathrm{U} / \mathrm{kg}$. The log-transformed endpoints were analysed using a linear mixed model, with treatment as a fixed effect and subject as a random effect, with variance parameters depending on treatment. Within- and between-subject coefficient of variations in percent $(\mathrm{CV} \%)$ were estimated and compared assuming an F-distribution of the variance ratio.

\subsubsection{Analysis of Relative Bioavailability}

In order to assess the relative bioavailability between faster aspart and insulin aspart combined for all three dose levels, $\mathrm{AUC}_{\mathrm{IAsp}, 0-t}$ was log-transformed and analysed using a linear mixed model, with period and treatment as fixed effects, log-dose as a covariate, and subject as a random effect. Similar bioavailability for faster aspart and insulin aspart was claimed if the $90 \% \mathrm{CI}$ for the treatment ratio was fully within $0.80-1.25[18,19]$.

\subsubsection{Analysis of the Relationship between Pharmacokinetics and Pharmacodynamics}

In order to investigate the relationship between exposure and glucose-lowering effect for faster aspart, $\mathrm{AUC}_{\mathrm{GIR}, 0-t}$ and $\mathrm{GIR}_{\max }$ were log-transformed and analysed in a linear mixed model, with subject as a fixed effect and $\log -\mathrm{AUC}_{\mathrm{IAsp}, 0-t}$ or $\log -\mathrm{C}_{\max }$, respectively, as a covariate.

\section{Results}

\subsection{Subjects}

Of 53 subjects screened, 46 were randomised and treated and 43 completed the trial (Fig. 1). Two subjects withdrew consent after three and four dosing visits, respectively, and one subject was withdrawn after seven dosing visits due to not being able to attend the next scheduled visit. The mean ( \pm standard deviation) age of the 46 randomised subjects was $44.0( \pm 10.4)$ years. The majority of subjects were male $(76.1 \%)$ and all were White. Mean body weight was $77.4( \pm 10.8) \mathrm{kg}$ and mean BMI was $24.6( \pm 2.4) \mathrm{kg} / \mathrm{m}^{2}$. Mean duration of diabetes was $20.8( \pm 10.0)$ years, and mean $\mathrm{HbA}_{1 \mathrm{c}}$ at baseline was $7.4 \%( \pm 0.8 \%)$. At entry into the study, 30 subjects were treated with multiple daily injection therapy and 16 subjects used continuous subcutaneous insulin infusion.

\subsection{Onset, Early Exposure and Early Glucose- Lowering Effect}

A left-shift of the mean serum insulin aspart concentrationtime profile was observed for faster aspart compared with insulin aspart at all three dose levels (Fig. 2). Likewise, the glucose-lowering effect profile was shifted to the left for faster aspart versus insulin aspart across the three dose levels (Fig. 3).

Across all three dose levels, onset of appearance occurred approximately twice as fast for faster aspart compared with insulin aspart, and $t_{\text {Early }} 50 \%$ Cmax was also earlier with faster aspart than with insulin aspart (Fig. 4a and Online Resource 1, Table S2). Early insulin exposure was consistently greater for faster aspart than for insulin aspart within the first $30 \mathrm{~min}$ after dosing, irrespective of dose level, as shown by the greater $\mathrm{AUC}_{\mathrm{IAsp}, 0-15 \min }$ and $\mathrm{AUC}_{\mathrm{IAsp}, 0-30 \mathrm{~min}}$ for faster aspart versus insulin aspart (Fig. 5a).

Onset of action occurred 5-6 min faster, and $t_{\text {Early }} 50 \%$ GIRmax also occurred earlier, with faster aspart than with insulin aspart across all three doses (Fig. $4 \mathrm{~b}$ and Online Resource 1, Table S3). Early glucose-lowering effect was consistently greater for faster aspart than for insulin aspart at all three dose levels, as shown by the greater partial $\mathrm{AUC}_{\mathrm{GIR}}$ 's for faster aspart versus insulin aspart within the first $2 \mathrm{~h}$ after dosing, except for $\mathrm{AUC}_{\mathrm{GIR}, 0-30 \mathrm{~min}}$ and $\mathrm{AUC}_{\mathrm{GIR}, 0-2 \mathrm{~h}}$ at $0.1 \mathrm{U} / \mathrm{kg}$ (Fig. 5b).

Estimated means as well as treatment ratios and/or differences for faster aspart versus insulin aspart are shown for all pharmacokinetic and pharmacodynamic endpoints in Online Resource 1, Tables S2 and S3. 

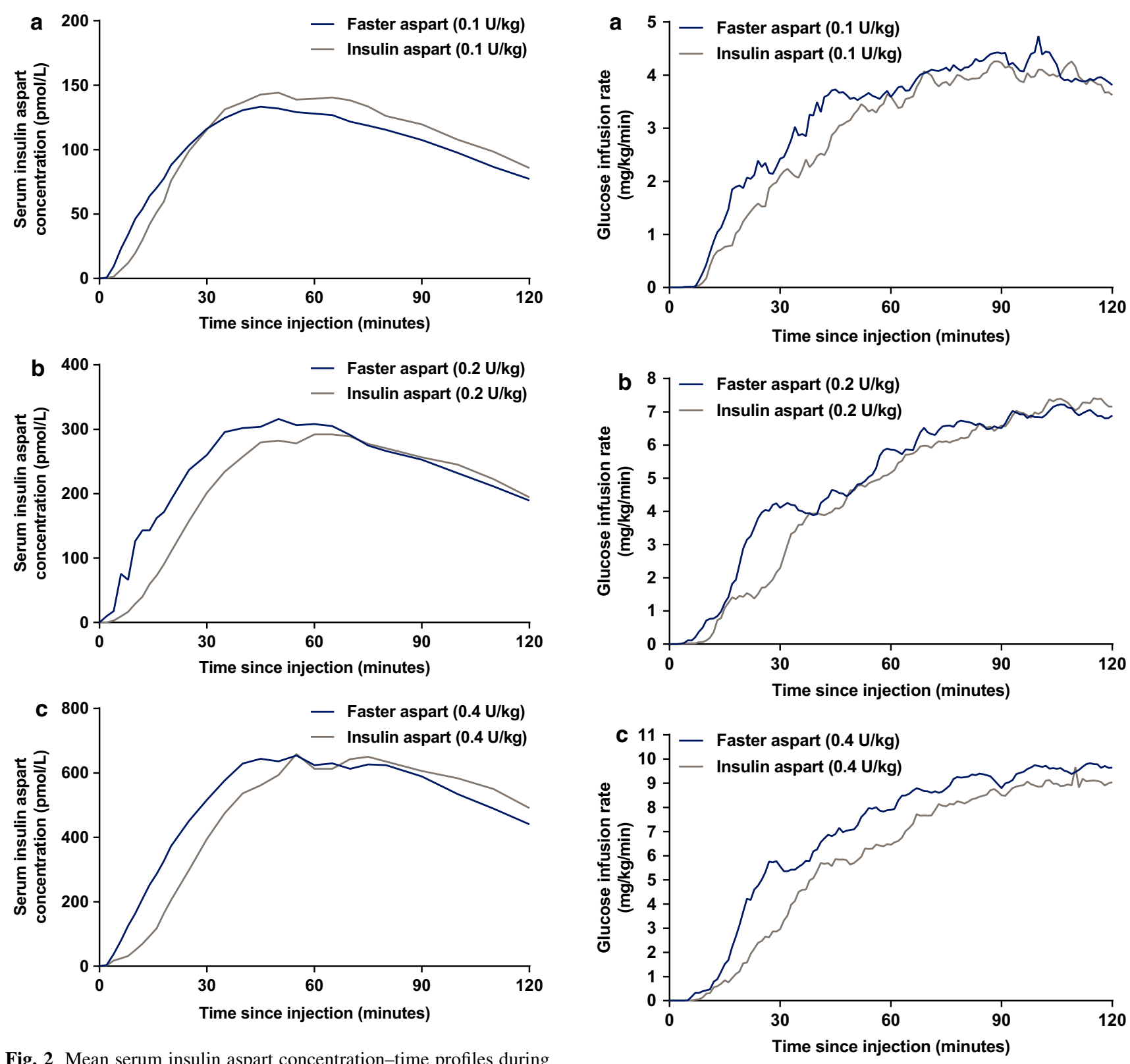

Fig. 2 Mean serum insulin aspart concentration-time profiles during the early phase $(0-2 \mathrm{~h})$ for faster aspart versus insulin aspart at three different dose levels: a $0.1 \mathrm{U} / \mathrm{kg} ; \mathbf{b} 0.2 \mathrm{U} / \mathrm{kg}$ and c $0.4 \mathrm{U} / \mathrm{kg}$

\subsection{Dose-Concentration and Dose-Response}

Mean 5-h serum insulin concentration-time profiles for faster aspart and insulin aspart at $0.1,0.2$ and $0.4 \mathrm{U} / \mathrm{kg}$ are presented in Fig. 6 and show that insulin exposure increased with increasing dose. Analysis of dose proportionality for faster aspart indicated that the increases in $\mathrm{AUC}_{\mathrm{IAsp}, 0-t}$ and $C_{\max }$ with increasing dose of faster aspart were slightly greater than dose proportional, as the mean and $95 \%$ CIs for the log-dose slopes were $1.21(1.15-1.26$, $p<0.001)$ for $\mathrm{AUC}_{\mathrm{IAsp}, 0-t}$, and $1.18 \quad(1.10-1.25$, $p<0.001)$ for $C_{\max }$, i.e. slightly different from 1.00 . However, the same was observed for insulin aspart [1.20

Fig. 3 Mean glucose infusion rate profiles during the early phase $(0-2 \mathrm{~h})$ for faster aspart versus insulin aspart at three different dose levels: a $0.1 \mathrm{U} / \mathrm{kg}$; b $0.2 \mathrm{U} / \mathrm{kg}$ and c $0.4 \mathrm{U} / \mathrm{kg}$

(1.14-1.25), $p<0.001, \quad$ for $\mathrm{AUC}_{\mathrm{IAsp}, 0-t} ;$ and 1.08 (1.00-1.16), $p=0.052$, for $\left.C_{\max }\right]$, and the departures from dose proportionality did not differ statistically significantly between faster aspart and insulin aspart for $\mathrm{AUC}_{\mathrm{IAsp}, 0-t}$ $(p=0.809)$ or $C_{\max }(p=0.094)$. In quantitative terms, a log-dose slope of 1.21 corresponds to a $12 \%$ increase in total exposure following a $10 \%$ increase in the faster aspart dose.

Mean 5-h glucose infusion rate profiles for faster aspart and insulin aspart at $0.1,0.2$ and $0.4 \mathrm{U} / \mathrm{kg}$ are presented in Fig. 7 and show that the glucose-lowering effect increased with increasing dose. The total glucose-lowering effect 
(a)

Onset of exposure

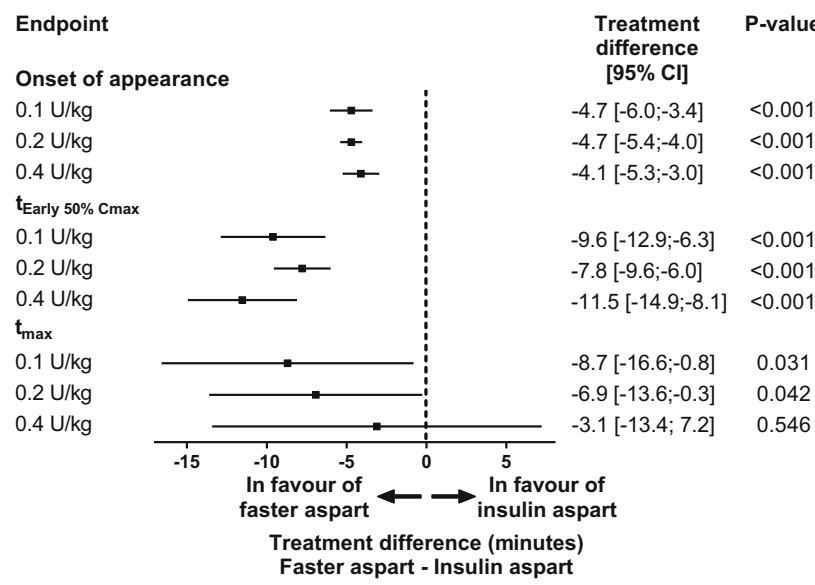

(b)

\section{Onset of glucose-lowering effect}

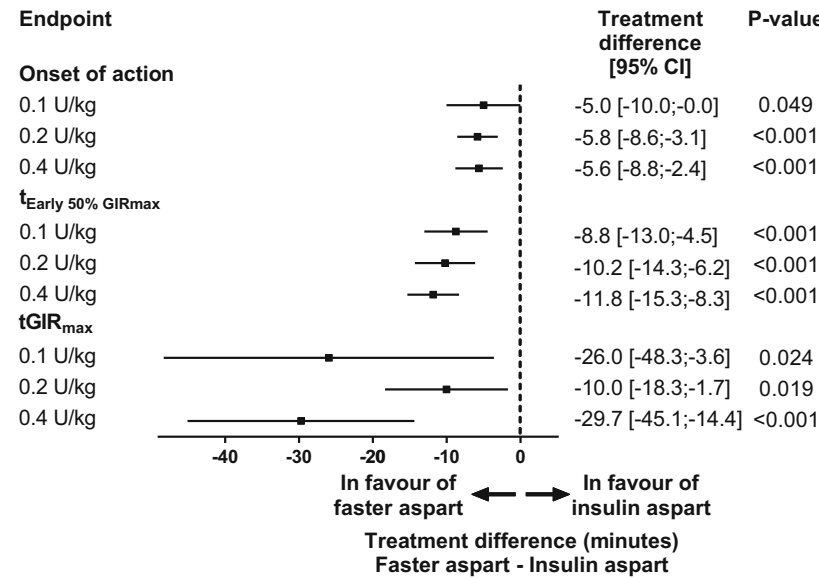

Fig. 4 a Onset of exposure and $\mathbf{b}$ onset of glucose-lowering effect for faster aspart versus insulin aspart. $C I$ confidence interval, $t_{\text {Early } 50 \% \text { Cmax }}$ time to $50 \%$ of maximum insulin aspart concentration in the early part of the pharmacokinetic profile, $t_{\text {Early } 50 \% \text { GIRmax }}$ time to $50 \%$ of maximum glucose infusion rate in the early part of the glucose infusion rate profile, $t G I R_{\max }$ time to maximum glucose infusion rate, $t_{\max }$ time to maximum insulin aspart concentration

$\left(\mathrm{AUC}_{\mathrm{GIR}, 0-t}\right)$ for both faster aspart and insulin aspart was approximately twice as high at the $0.2 \mathrm{U} / \mathrm{kg}$ dose than at the $0.1 \mathrm{U} / \mathrm{kg}$ dose (Table 1). In contrast, $\mathrm{AUC}_{\mathrm{GIR}, 0-t}$ for the $0.4 \mathrm{U} / \mathrm{kg}$ dose was only $73 \%$ larger than for the $0.2 \mathrm{U} / \mathrm{kg}$ dose level for both faster aspart and insulin aspart, i.e. less than expected for a doubling of the dose. The estimates of GIR $_{\max }$ also showed a levelling off with increasing dose for both treatments (Online Resource 1, Table S3), suggesting that some subjects approached a maximum plateau of insulin action at the higher insulin dose of $0.4 \mathrm{U} / \mathrm{kg}$. Accordingly, analysis of dose linearity indicated that the increases in $\mathrm{AUC}_{\mathrm{GIR}, 0-t}$ and $\mathrm{GIR}_{\max }$ with increasing dose were slightly less than linear $\left(p<0.01\right.$ for $\mathrm{AUC}_{\mathrm{GIR}, 0-t}$, and $p<0.001$ for $\mathrm{GIR}_{\max }$ ). The coefficients of the function describing the dose-response relationship were not (a)

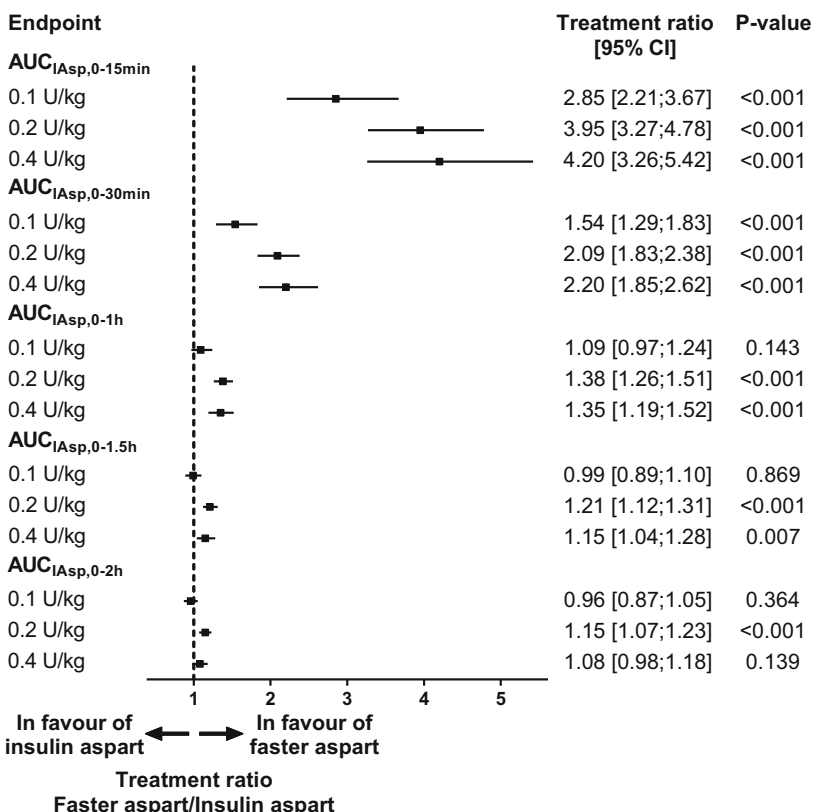

(b)

Early glucose-lowering effect

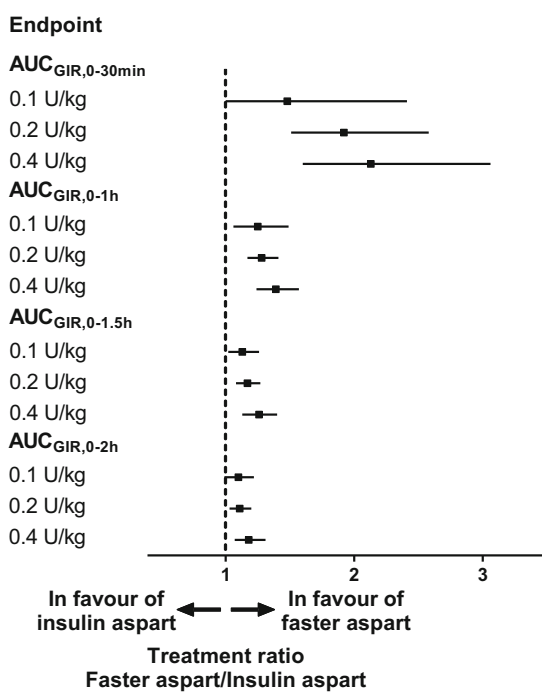

Fig. 5 a Early exposure and b early glucose-lowering effect for faster aspart versus insulin aspart. AUC area under the curve, $C I$ confidence interval, GIR glucose infusion rate, IAsp insulin aspart

statistically significantly different between faster aspart and insulin aspart for $\mathrm{AUC}_{\mathrm{GIR}, 0-t}(p=0.786)$ and $\mathrm{GIR}_{\max }$ $(p=0.944)$.

\subsection{Within- and Between-Subject Variability in Glucose-Lowering Effect}

Within-subject day-to-day variability for faster aspart was low for early, total and maximum glucose-lowering effect, and did not differ statistically significantly from insulin 
(a)

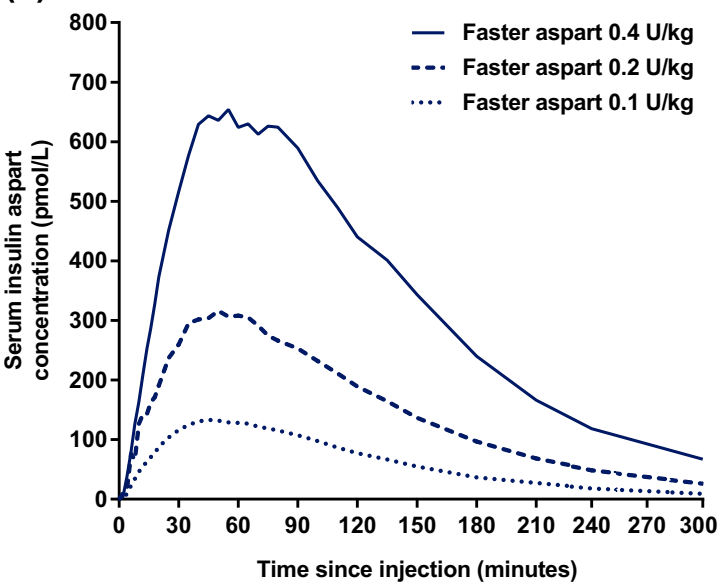

(b)

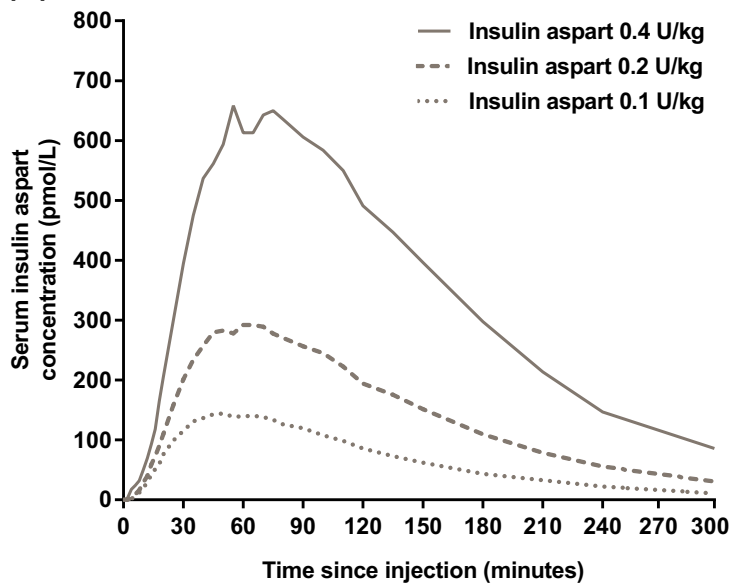

Fig. 6 Mean serum insulin aspart concentration-time profiles ( $0-5$ h) for $\mathbf{a}$ faster aspart and $\mathbf{b}$ insulin aspart at three different dose levels

(a)

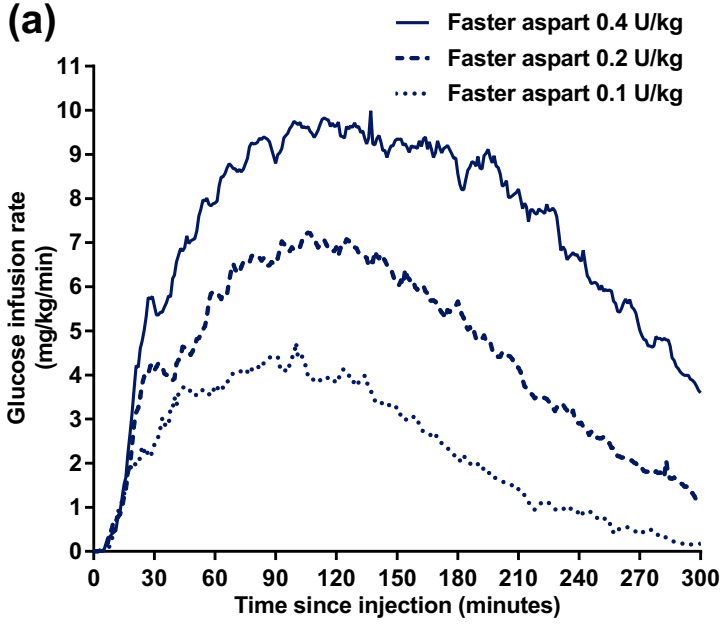

(b)

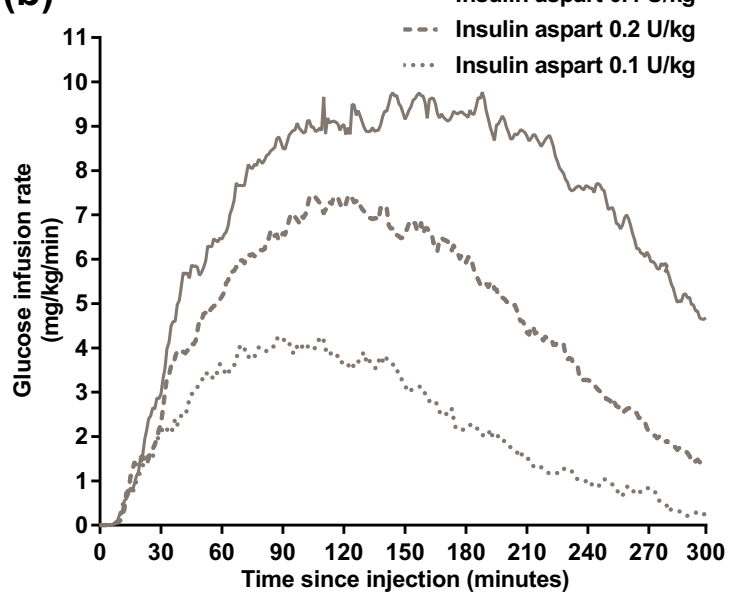

Fig. 7 Mean glucose infusion rate profiles $(0-5$ h) for $\mathbf{a}$ faster aspart and $\mathbf{b}$ insulin aspart at three different dose levels

Table 1 Dose-response relationship for total glucose-lowering effect for faster aspart and insulin aspart

\begin{tabular}{|c|c|c|c|c|}
\hline & $\begin{array}{l}\text { Faster } \\
\text { aspart }\end{array}$ & $\begin{array}{l}\text { Insulin } \\
\text { aspart }\end{array}$ & $\begin{array}{l}\text { Faster } \\
\text { aspart }\end{array}$ & $\begin{array}{l}\text { Insulin } \\
\text { aspart }\end{array}$ \\
\hline & \multicolumn{2}{|c|}{ Least square mean } & \multicolumn{2}{|c|}{ Dose ratio $[95 \% \mathrm{CI}]$} \\
\hline \multicolumn{5}{|c|}{$\mathrm{AUC}_{\mathrm{GIR}, 0-\mathrm{t}}(\mathrm{mg} / \mathrm{kg})$} \\
\hline $0.1 \mathrm{U} / \mathrm{kg}$ & 646.8 & 656.1 & \multirow{3}{*}{$\begin{array}{l}2.09[1.92 ; 2.28]^{\mathrm{a}} \\
1.73[1.59 ; 1.88]^{\mathrm{b}}\end{array}$} & \multirow{3}{*}{$\begin{array}{l}2.12[1.95 ; 2.31]^{\mathrm{a}} \\
1.73[1.59 ; 1.89]^{\mathrm{b}}\end{array}$} \\
\hline $0.2 \mathrm{U} / \mathrm{kg}$ & 1352.8 & 1391.1 & & \\
\hline $0.4 \mathrm{U} / \mathrm{kg}$ & 2338.7 & 2410.2 & & \\
\hline
\end{tabular}

$A U C$ area under the curve, $C I$ confidence interval, GIR glucose infusion rate, $t$ time of last GIR observation $>0$

${ }^{a}$ Ratio 0.2/0.1 U/kg

${ }^{\mathrm{b}}$ Ratio $0.4 / 0.2 \mathrm{U} / \mathrm{kg}$ 
Table 2 Within-subject variability in glucose-lowering effect for faster aspart versus insulin aspart

\begin{tabular}{llll}
\hline & \multicolumn{2}{c}{ Coefficient of variation $(\%)$} & $p$ value \\
\cline { 2 - 3 } & Faster aspart & Insulin aspart & \\
\hline \multicolumn{2}{l}{ Early glucose-lowering effect } & \\
AUC $_{\text {GIR,0-1h }}$ & 25.5 & 21.6 & 0.291 \\
AUC $_{\text {GIR,0-2h }}$ & 20.4 & 17.9 & 0.401 \\
Overall glucose-lowering effect & & \\
AUC $_{\text {GIR,0-t }}$ & 18.3 & 18.4 & 0.947 \\
GIR $_{\text {max }}$ & 19.3 & 21.0 & 0.593 \\
\hline
\end{tabular}

Coefficient of variation data are model-based estimates

$A U C$ area under the curve, GIR glucose infusion rate, GIR $R_{\max }$ maximum glucose infusion rate, $t$ time of last GIR observation $>0$

aspart (Table 2). Results on between-subject variability for early, total and maximum glucose-lowering effect are provided in Online Resource 1, Table S4, and showed no statistically significant differences between faster aspart and insulin aspart.

\subsection{Relative Bioavailability and Overall Glucose- Lowering Effect}

The estimated treatment ratio and $90 \% \mathrm{CI}$ of faster aspart versus insulin aspart for $\mathrm{AUC}_{\mathrm{IAsp}, 0-t}$ for all three dose levels together were 0.97 (0.94-1.01). Thus, the bioavailability of faster aspart was similar to insulin aspart as the $90 \% \mathrm{CI}$ for $\mathrm{AUC}_{\mathrm{IAsp}, 0-t}$ was fully within the interval of 0.80-1.25.

$\mathrm{AUC}_{\mathrm{GIR}, 0-t}$ and $\mathrm{GIR}_{\max }$ were both comparable for faster aspart and insulin aspart at all three dose levels, with all treatment ratios being close to 1.00 (Online Resource 1, Table S3), suggesting similar total glucose-lowering effects for faster aspart and insulin aspart when administered at identical dose levels.

\subsection{Relationship between Pharmacokinetics and Pharmacodynamics}

The relationships between total exposure $\left(\mathrm{AUC}_{\mathrm{IAsp}, 0-t}\right)$ and total glucose-lowering effect $\left(\mathrm{AUC}_{\mathrm{GIR}, 0-t}\right)$, and between $C_{\text {max }}$ and GIR $_{\text {max }}$, for faster aspart are presented in Online Resource 1, Fig. S2. From the coefficient of determination $\left(R^{2}\right)$, approximately $50 \%$ of the variability in total and maximum glucose-lowering effect could be explained by total exposure and maximum concentration, respectively.

\subsection{Safety}

Both faster aspart and insulin aspart were well tolerated and no safety issues were observed during the trial. There were no clinically significant findings in safety laboratory parameters, vital signs, physical examination or electrocardiogram, and no confirmed hypoglycaemic episodes or injection site reactions occurred during the trial.

\section{Discussion}

The key finding of this trial was that across three different clinically relevant dose levels, faster aspart showed faster onset of exposure and greater early exposure, which led to faster onset of action and greater early glucose-lowering effect compared with insulin aspart.

With the left-shift of the pharmacokinetic and pharmacodynamic time profiles, faster aspart better replicates the physiological insulin action profile in response to a meal than insulin aspart. This finding may imply that faster aspart has the potential to provide clinical benefits over current rapid-acting insulin analogues in terms of improved postprandial glucose control in subjects with diabetes. Indeed, in a phase III study in subjects with T1DM treated in a basal-bolus regimen, faster aspart showed superiority over insulin aspart with respect to change from baseline in 2-h postprandial glucose increments in a standardised meal test [20]. In addition, a statistically significant difference in favour of faster aspart was observed with respect to change from baseline in 1-h postprandial glucose increments. Consistent with the pharmacodynamic time profiles of faster aspart versus insulin aspart, the treatment difference in the meal-test was more pronounced after $1 \mathrm{~h}$ than after $2 \mathrm{~h}$ [20]. In the same study, $\mathrm{HbA}_{1 \mathrm{c}}$ reduction was shown to be statistically significantly greater for faster aspart versus insulin aspart [20]. In another phase III study in subjects with T2DM treated in a basal-bolus regimen plus metformin, the reduction from baseline in 1-h postprandial glucose increments was statistically significantly greater for faster aspart versus insulin aspart in a meal-test, while the difference in the reduction from baseline in 2-h postprandial glucose increments in favour of faster aspart did not reach statistical significance [21]. In that study, noninferiority in $\mathrm{HbA}_{1 \mathrm{c}}$ reduction was demonstrated for faster aspart versus insulin aspart [21]. No statistically significant differences were observed in overall rate of severe or confirmed hypoglycaemia in either of the two studies [20, 21].

Current rapid-acting insulins provide the best possible prandial glucose control if administered approximately 15 min before the start of the meal to compensate for the lag time occurring from subcutaneous injection until sufficient insulin has been absorbed into the circulation to handle the carbohydrate uptake after meal ingestion [7, 8]. Despite this, a lot of patients with diabetes use no, or only a very limited, injection-meal interval in line with approved 
labelling [9]. The improved pharmacodynamic properties of faster aspart versus insulin aspart would be expected to facilitate mealtime dosing, thereby reducing the need for an injection-meal interval with faster aspart. Moreover, the pharmacodynamic properties of faster aspart may open for the option of postmeal dosing when needed. Thus, treatment with faster aspart at $20 \mathrm{~min}$ postmeal has been investigated and showed non-inferior $\mathrm{HbA}_{1 \mathrm{c}}$ reduction versus insulin aspart administered at mealtime in addition to comparable overall rates of severe and confirmed hypoglycaemia in subjects with T1DM [20].

In the current study, it is reassuring to observe that the within-subject variability in early, as well as total, glucoselowering effect was at the same low level for faster aspart as for insulin aspart, being in the range of $18-25 \%$. Insulin aspart has previously been shown to have a within-subject variability in glucose-lowering effect of approximately $15-25 \%$, which is comparable to that of regular human insulin, insulin lispro and insulin glulisine [22-25]. This is in contrast to the somewhat higher within-subject variability in glucose-lowering effect of 48-99\% reported for several basal insulin preparations, such as insulin glargine $100 \mathrm{U} / \mathrm{mL}$, neutral protamine hagedorn (NPH) insulin and protaminated insulin lispro [26-28]. At the same time, it is on par with the within-subject variability of 20 and $27 \%$ shown for insulin degludec and insulin detemir, respectively $[26,27]$. With the relatively low variability in glucose-lowering effect of faster aspart between subsequent administrations, it is anticipated that its faster onset and greater early exposure and glucose-lowering effect will be consistent from day to day in clinical practice. Betweensubject variability was also shown to be comparable for faster aspart and insulin aspart in the current study, although this is less clinically relevant since insulin should always be titrated according to individual needs.

We have no immediate explanation for the fact that the increase in $\mathrm{AUC}_{\mathrm{IAsp}, 0-t}$ and $C_{\max }$ with increasing dose of faster aspart was slightly greater than dose proportional. The same was observed for insulin aspart in the present study and has also been previously observed for the insulin aspart component of insulin degludec/insulin aspart [29]. The deviation from dose proportionality observed in the present study corresponds to a $12 \%$ increase in total exposure and maximum concentration in response to a $10 \%$ increase in the faster aspart dose. Such a minor deviation is not considered to impose any practical implications in the clinical setting.

We observed a slight levelling off for both $\mathrm{AUC}_{\mathrm{GIR}, 0-t}$ and $\mathrm{GIR}_{\max }$ when the dose increased from 0.2 to $0.4 \mathrm{U} / \mathrm{kg}$ of faster aspart and insulin aspart. The same has been observed previously in dose-response studies with regular human insulin, insulin glulisine and insulin aspart at dose levels of $0.3-0.35 \mathrm{U} / \mathrm{kg}$, presumably indicating saturation of glucose-lowering effect in some subjects [30, 31]. Thus, at dose levels of $0.3-0.4 \mathrm{U} / \mathrm{kg}$, some subjects may approach their maximum rate of insulin-stimulated glucose disposal, which on average lies in the range of $10-15 \mathrm{mg} / \mathrm{kg} / \mathrm{min}[32,33]$. However, it is important to note that saturation of glucose-lowering effect is mainly an experimental phenomenon caused by the fixed-dose levels administered in a glucose clamp study. In the clinical setting, individual insulin titration should ensure that subjects remain on the linear part of their insulin dose-response curve.

In the present study, $C_{\max }$ for the $0.1 \mathrm{U} / \mathrm{kg}$ dose was slightly lower, and $C_{\max }$ for the $0.2 \mathrm{U} / \mathrm{kg}$ dose was slightly higher, for faster aspart versus insulin aspart. This implied that $t_{\text {Early }} 50 \% \mathrm{Cmax}$ for faster aspart relative to insulin aspart was slightly underestimated at the $0.1 \mathrm{U} / \mathrm{kg}$ dose, and slightly overestimated at the $0.2 \mathrm{U} / \mathrm{kg}$ dose [34]. However,

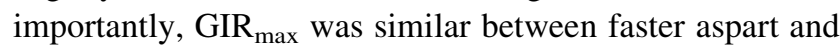
insulin aspart at all three dose levels. Therefore, a fully reliable comparison between treatments was possible for the corresponding pharmacodynamic endpoint, $t_{\text {Early }} 50 \%$ GIRmax, showing a consistently shorter time to achieve half maximum glucose-lowering effect for faster aspart versus insulin aspart.

\section{Conclusions}

In the current study comparing the pharmacological characteristics of faster aspart and insulin aspart in subjects with T1DM, faster aspart showed faster onset and greater early insulin exposure and glucose-lowering effect versus insulin aspart across a clinically relevant dose range. The ultra-fast-acting properties of faster aspart were consistently observed from day to day. The results of the current pharmacokinetic/pharmacodynamic study appear to translate to the clinical setting as larger phase III trials show that faster aspart provides clinical benefits over insulin aspart in terms of improved postprandial glucose control [20, 21].

Acknowledgements The authors would like to thank Alexandru L. Dinita, MD, Novo Nordisk A/S, for his review and input to the manuscript, and Carsten Roepstorff, PhD, CR Pharma Consult, Copenhagen, Denmark, for providing medical writing support, which was funded by Novo Nordisk A/S.

\section{Compliance with Ethical Standards}

All procedures performed in studies involving human participants were in accordance with the ethical standards of the institutional and/ or national research committee and with the 1964 Helsinki declaration and its later amendments or comparable ethical standards. Informed consent was obtained from all individual participants included in the study.

Funding This study was funded by Novo Nordisk A/S. 
Conflict of interest Tim Heise is shareholder of Profil, which received research funds from Adocia, AstraZeneca, Becton-Dickinson, Biocon, Boehringer Ingelheim, Dance Biopharm, Eli Lilly, Grünenthal, Gulf Pharmaceutical Industries, Johnson \& Johnson, Marvel, MedImmune, Medtronic, Novartis, Novo Nordisk, Roche Diagnostics, Sanofi, Senseonics and Zealand Pharma. In addition, he is also a member of advisory panels for Novo Nordisk and received speaker honoraria and travel grants from Eli Lilly, Mylan and Novo Nordisk. Kirstine Stender-Petersen, Jacob Bonde Jacobsen and Hanne Haahr are employees and shareholders of Novo Nordisk. Eric Zijlstra received travel grants from Dance Biopharm and Novo Nordisk, and speaker honoraria from Novo Nordisk and Roche Diabetes Care. Ulrike Hövelmann and Leszek Nosek declare no conflicts of interest.

Open Access This article is distributed under the terms of the Creative Commons Attribution-NonCommercial 4.0 International License (http://creativecommons.org/licenses/by-nc/4.0/), which permits any noncommercial use, distribution, and reproduction in any medium, provided you give appropriate credit to the original author(s) and the source, provide a link to the Creative Commons license, and indicate if changes were made.

\section{References}

1. Monnier L, Lapinski H, Colette C. Contributions of fasting and postprandial plasma glucose increments to the overall diurnal hyperglycemia of type 2 diabetic patients. Variations with increasing levels of $\mathrm{HbA}_{1 \mathrm{c}}$. Diabetes Care. 2003;26:881-5.

2. Woerle HJ, Neumann C, Zschau S, et al. Impact of fasting and postprandial glycemia on overall glycemic control in type 2 diabetes Importance of postprandial glycemia to achieve target HbA1c levels. Diabetes Res Clin Pract. 2007;77:280-5.

3. Heise T. Getting closer to physiologic insulin secretion. Clin Ther. 2007;29:S161-5.

4. Sheldon B, Russell-Jones D, Wright J. Insulin analogues: an example of applied medical science. Diabetes Obes Metab. 2009;11:5-19.

5. Home PD. The pharmacokinetics and pharmacodynamics of rapid-acting insulin analogues and their clinical consequences. Diabetes Obes Metab. 2012;14:780-8.

6. Hermansen K, Bohl M, Schioldan AG. Insulin aspart in the management of diabetes mellitus: 15 years of clinical experience. Drugs. 2016;76:41-74.

7. Luijf YM, van Bon AC, Hoekstra JB, Devries JH. Premeal injection of rapid-acting insulin reduces postprandial glycemic excursions in type 1 diabetes. Diabetes Care. 2010;33:2152-5.

8. Heinemann L, Muchmore DB. Ultrafast-acting insulins: state of the art. J Diabetes Sci Technol. 2012;6:728-42.

9. Overmann H, Heinemann L. Injection-meal interval: recommendations of diabetologists and how patients handle it. Diabetes Res Clin Pract. 1999;43:137-42.

10. Food and Drug Administration. Inactive ingredient search for approved drug products. Available at: http://www.accessdata.fda. gov/scripts/cder/iig/index.cfm. Accessed 21 Oct 2016.

11. Heise T, Hövelmann U, Brøndsted L, Adrian CL, Nosek L, Haahr $\mathrm{H}$. Faster-acting insulin aspart: earlier onset of appearance and greater early pharmacokinetic and pharmacodynamic effects than insulin aspart. Diabetes Obes Metab. 2015;17:682-8.

12. Vora J, Heise T. Variability of glucose-lowering effect as a limiting factor in optimizing basal insulin therapy: a review. Diabetes Obes Metab. 2013;15:701-12.

13. Heinemann L. Variability of insulin action: does it matter? Insulin. 2008;3:37-45.
14. Swinnen SG, Holleman F, DeVries JH. The interpretation of glucose clamp studies of long-acting insulin analogues: from physiology to marketing and back. Diabetologia. 2008;51:1790-5.

15. Benesch C, Heise T, Klein O, Heinemann L, Arnolds S. How to assess the quality of glucose clamps? Evaluation of clamps performed with ClampArt, a novel automated clamp device. J Diabetes Sci Technol. 2015;9:792-800.

16. American Diabetes Association. Defining and reporting hypoglycaemia in diabetes: a report from the American Diabetes Association Workgroup on Hypoglycaemia. Diabetes Care. 2005;28:1245-9.

17. Fieller EC. Some problems in interval estimation. J R Stat Soc Series B Stat Methodol. 1954;16:175-85.

18. European Medicines Agency. Committee for Medicinal Products for Human Use. Guideline on the investigation of bioequivalence. CPMP/EWP/QWP/1401/98 Rev. 1/Corr. 2010. Available at: http://www.ema.europa.eu/docs/en_GB/document_library/ Scientific_guideline/2010/01/WC500070039.pdf. Accessed 21 Oct 2016.

19. Food and Drug Administration. Code of Federal Regulations. 21 CFR Part 320. Bioavailability and bioequivalence requirements. Available at: http://www.ecfr.gov/cgi-bin/text-idx?SID= b77b9e6e4aea3cdbd753c6bbd1b98077\&mc=true \&node=pt21.5. 320\&rgn=div5. Accessed 21 Oct 2016.

20. Russell-Jones D, Bode B, de Block C, et al. Double-blind mealtime faster-acting insulin aspart vs insulin aspart in basalbolus improves glycemic control in T1D: the Onset ${ }^{\circledR} 1$ Trial. Diabetes. 2016;65(Suppl. 1):A77.

21. Bowering K, Case C, Harvey J, et al. Faster-acting insulin aspart vs insulin aspart as part of basal-bolus therapy improves postprandial glycemic control in uncontrolled T2D in the DoubleBlinded Onset ${ }^{\circledR} 2$ Trial. Diabetes. 2016;65(Suppl. 1):A63.

22. Heinemann L, Weyer C, Rauhaus M, Heinrichs S, Heise T. Variability of the metabolic effect of soluble insulin and the rapid-acting insulin analog insulin aspart. Diabetes Care. 1998;21:1910-4.

23. Ziel FH, Davidson MB, Harris MD, Rosenberg CS. The variability in the action of unmodified insulin is more dependent on changes in tissue insulin sensitivity than on insulin absorption. Diabet Med. 1988;5:662-6.

24. de la Peña A, Seger M, Soon D, et al. Bioequivalence and comparative pharmacodynamics of insulin lispro $200 \mathrm{U} / \mathrm{mL}$ relative to insulin lispro (Humalog ${ }^{\circledR}$ ) $100 \mathrm{U} / \mathrm{mL}$. Clin Pharmacol Drug Dev. 2016;5:69-75.

25. Becker RH, Frick AD. Clinical pharmacokinetics and pharmacodynamics of insulin glulisine. Clin Pharmacokinet. 2008;47:7-20.

26. Heise T, Hermanski L, Nosek L, Feldman A, Rasmussen S, Haahr H. Insulin degludec: four times lower pharmacodynamic variability than insulin glargine under steady-state conditions in type 1 diabetes. Diabetes Obes Metab. 2012;14:859-64.

27. Heise T, Nosek L, Rønn BB, et al. Lower within-subject variability of insulin detemir in comparison to NPH insulin and insulin glargine in people with type 1 diabetes. Diabetes. 2004;53:1614-20.

28. Ocheltree SM, Hompesch M, Wondmagegnehu ET, Morrow L, Win K, Jacober SJ. Comparison of pharmacodynamic intrasubject variability of insulin lispro protamine suspension and insulin glargine in subjects with type 1 diabetes. Eur J Endocrinol. 2010;163:217-23.

29. Heise T, Nosek L, Klein O, Coester H, Svendsen AL, Haahr H. Insulin degludec/insulin aspart produces a dose-proportional glucose-lowering effect in subjects with type 1 diabetes mellitus. Diabetes Obes Metab. 2015;17:659-64.

30. Becker RH, Frick AD, Nosek L, Heinemann L, Rave K. Doseresponse relationship of insulin glulisine in subjects with type 1 diabetes. Diabetes Care. 2007;30:2506-7. 
31. Nosek L, Roggen K, Heinemann L, et al. Insulin aspart has a shorter duration of action than human insulin over a wide doserange. Diabetes Obes Metab. 2013;15:77-83.

32. DeFronzo RA, Ferrannini E, Hendler R, Felig P, Wahren J. Regulation of splanchnic and peripheral glucose uptake by insulin and hyperglycemia in man. Diabetes. 1983;32:35-45.

33. Freidenberg GR, Suter SL, Henry RR, Reichart D, Olefsky JM. In vivo stimulation of the insulin receptor kinase in human skeletal muscle. Correlation with insulin-stimulated glucose disposal during euglycemic clamp studies. J Clin Invest. 1991;87: 2222-9.

34. Jain L, Parks MH, Sahajwalla C. Determination of time to onset and rate of action of insulin products: importance and new approaches. J Pharm Sci. 2013;102:271-9. 